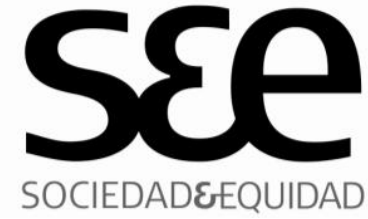

\section{Cibermilitancia 2.0 La juventud kirchnerista en la Argentina de hoy}

\author{
Cibermilitancia 2.0 Youth Kirchner in Argentina today
}

$\begin{array}{ll}\text { Nombre: } & \text { Natalia Garrido }\left(^{1}\right) \\ \text { Filiación: } & \text { UBA-CONICET } \\ \text { País: } & \text { Argentina } \\ \text { Correo: } & \text { nagarridos@gmail.com }\end{array}$

\title{
RESUMEN
}

El presente artículo se propone realizar una aproximación a la relación que existe hoy entre juventudes, participación política y nuevas tecnologías de la información y la comunicación (TIC). En particular, hará referencia a ciertas singularidades que se advertirían en los modos de participación de las juventudes kirchneristas de Buenos Aires. Para ello se consideran los avances de investigación realizados a partir de entrevistas semi-estructuradas a jóvenes de 18 a 30 años que utilizan frecuentemente las TIC para la participación política. En los últimos años el interés por la participación política de las juventudes ha sido un tema de importancia social en los más variados ámbitos. Del mismo modo, ha crecido el peso y reconocimiento del sujeto joven como sujeto político relevante para el actual proceso político, buscando poder proyectarse al futuro. El marco en el que se inscribe dicha participación sería el de un cambio de época que se distingue en varios países de Latinoamérica, así como ciertas transformaciones vinculadas con la "tercera Revolución industrial (informacional)" -basada en el uso generalizado de TIC- y el surgimiento de la denominada cibermilitancia.

\section{PALABRAS CLAVE}

Participación, juventudes, microcultura política, capitalismo informacional, espacio público, cibermilitancia.

\footnotetext{
${ }^{1}$ La autora es Maestranda en Comunicación y Cultura en la Universidad de Buenos Aires (UBA), becaria Doctoral del Consejo Nacional de Investigaciones Científicas y Técnicas Universidad de Buenos Aires (UBA). Sus líneas de investigación son: sociología de la juventud, sociología de la cultura y política latinoamericana.
} 


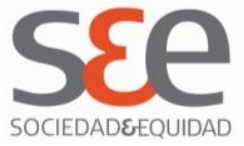

\section{ABSTRACT}

This article seeks to approach the current relationship between youth, political participation and new technologies of information and communication (ICT). In particular, it singles out certain singularities regarding the modes of participation of the kirchnerista youth in Buenos Aires. In order to achieve this reference will be made to research advances made through semi-structures interviews carried out with young people from 18 to 30 years old who frequently use ICT as a form of political participation. In recent years, the interest in youth political participation has been a subject of social importance in the most varied areas. Also, the young subject as a relevant political subject for the current political process has been recognized as important for future projections. The participation of interest here is situated in a change of era, that has been distinguished in several Latin American countries, regarding also transformations related to the "third industrial revolution (informational)", based on the widespread use of ICT-and the emergence of the so-called cibermilitance.

\section{KEYWORDS}

Participation, youth, political micro culture, informational capitalism, public space, cyber-activism.

\section{Cambio de época: movilización política y gobiernos posneoliberales en Latinoamérica}

En la última década, considerando el 19 y 20 de diciembre de 2001 como punto de inflexión de la hegemonía neoliberal, se ha reconocido reiteradamente el fenómeno de la politización de considerables sectores de la sociedad argentina. Adquirieron centralidad en el espacio público diversos movimientos y sectores sociales impugnadores del modelo neoliberal, y surgieron nuevas formas de participación política que ampliaron los límites de lo público. Asimismo, a partir del ascenso de nuevos gobiernos en nuestra región -Argentina (2003), Brasil (2003), Uruguay (2004), Bolivia (2006), Ecuador (2007), Paraguay (2008)-, se habla de un nuevo ciclo político desplegado en Latinoamérica, el cual desembocaría en un ciclo de gobiernos posneoliberales (García Linera, 2008; Sader, 2009), reflejo de que el "cambio de época" -como mencionara Rafael Correa- se estaba conformando.

En la década de los noventa, en nuestro país la participación fue en muchos casos una forma de resistencia frente al denominado discurso único y la fragmentación social resultante de una política desde los centros de poder dominantes. La irrupción de espacios culturales autogestionados y alternativos, por ejemplo, aparecía como una 


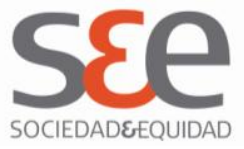

nueva manera de ocupar el espacio público a través de la acción colectiva (Wortman, 2009). Como afirma Longoni (2011), se trata de acciones generadas muchas veces de manera colectiva, utilizando recursos artísticos y saberes extra-artísticos para tomar posición e incidir en el territorio de lo político en tanto espacio del disenso. Asimismo, como reconoce la autora, condiciones tales como la mayor accesibilidad a Internet potenciaron en cierta medida el desarrollo de estos fenómenos colectivos y la producción de nuevos lenguajes.

Según un estudio del año 2008 en torno a la participación de las juventudes en la Ciudad Autónoma de Buenos Aires, en general la participación social y el ejercicio de la ciudadanía parecen despertar una adhesión escasa entre los jóvenes, y sólo un $14 \%$ de los jóvenes de la ciudad participaría efectivamente en alguna organización social, agrupación o grupo social (Encuesta Joven, 2008). Sin embargo, y aunque no contamos con datos cuantitativos actualizados respecto a dicha participación, existe cierto consenso en torno a que es posible reconocer -sobre todo a partir del 2008- un fenómeno de reciente politización en la sociedad argentina. A partir de esta premisa, la presente situación nos llevaría a realizar un desplazamiento en la discusión en torno al paradigma predominante de comprensión de la participación de las juventudes: los jóvenes como "apáticos" o “desinteresados" por los problemas de la sociedad. Este cambio de paradigma debería dejar de ocupar un lugar central para dar espacio a un nuevo debate que involucre el análisis de los contenidos y alcances de la participación como práctica transformadora de la realidad. Se trataría entonces de desentrañar representaciones y significados del concepto político de participación, que en los últimos años se ha constituido en una creencia central tanto en la sociedad y en los movimientos sociales como en la constitución del poder político desde las distintas instancias gubernamentales.

En los últimos años, el interés por la participación política de las juventudes ha sido un tema de importancia social en los más variados ámbitos. Del mismo modo, ha crecido el peso y reconocimiento del sujeto joven como sujeto político relevante para el actual proceso político, buscando poder proyectarse al futuro. Este fenómeno puede hacerse extensible a la mayoría de los países de Latinoamérica, ya sea por la incorporación de los jóvenes a la política partidaria o por su visibilización a partir de manifestaciones recientes, como en los casos de Chile y Colombia. Si bien el modo de participación de los jóvenes en los distintos casos se ve atravesado por la singularidad de los contextos políticos de sus respectivos países, pueden encontrarse elementos en común. En relación con las motivaciones de la participación, por ejemplo, el filósofo Martín Hopenhayn -haciendo referencia a los jóvenes de la región-, en una reciente entrevista, afirma que 


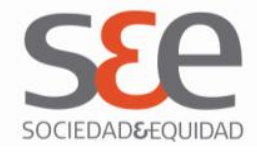

la juventud hoy en día aparece, o bien porque tiene un manejo de información que la hace sentirse más empoderada políticamente o bien porque la política se abrió como un campo que ya no responde a un pensamiento único. Hay una percepción mucho más generalizada de que la política deja de ser una especie de administración mecánica del aparato burocrático público para ser un espacio donde se pueden tomar decisiones para modificar la sociedad (Hopenhayn, 2012).

En este sentido, resulta relevante interrogarnos acerca de los nuevos modos de empoderamiento que se realizan en la denominada "Sociedad informacional" (Castells, 2001) y las características que asumen en la participación democrática.

\section{Transformaciones del sistema capitalista: industrias culturales y contenidos en la era del capitalismo informacional}

Como advierten diversos autores, con la "tercera revolución industrial" (informacional) la industria cultural y mediática asume un papel central, ya que ahora esta industria pasa a incidir en la producción misma del mercado y del trabajador (Dantas, 2003; Roldán, 2005). En cuanto a las transformaciones vinculadas al impacto tecnológico, se observa que la sofisticación de procesos de digitalización (a partir del desarrollo de tecnología orientada específicamente para este fin) facilita el intercambio de los más diversos bienes culturales, pero al mismo tiempo plantea nuevos interrogantes y desafíos tanto para las industrias culturales como para los ciudadanos que los consumen, producen y crean de manera colectiva.

La tendencia global a la concentración de los medios e industrias, característica primordial de esta fase del capitalismo, podría repercutir en la producción de contenidos, situación no tan sencilla de advertir o desentrañar (Miege, 2006). La importancia en torno a los contenidos se encuentra en el hecho de que dicho sector no posee sólo un interés de tipo económico, sino también en lo referido a la producción, reproducción y diversidad cultural, así como términos de pluralidad ideológico-política. Los medios, soportes y dinámicas de este sector no sólo intervienen sino que, incluso, conforman parte del denominado espacio público (Becerra, 2011) e inciden en los imaginarios y representaciones de los sujetos. Como bien señala Martín Becerra, esta situación atañe a dimensiones tales como la diversidad y el pluralismo de las producciones culturales, así como un debate abierto en relación con las regulaciones posibles y deseables. 


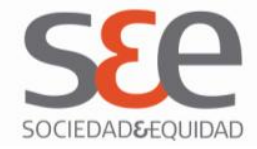

\section{Producciones culturales de las juventudes y TIC}

En la actualidad, si observamos las producciones culturales y colectivas realizadas por los/as propios/as jóvenes, aparecen ideas políticas concretas y perspectivas de futuro vinculadas a una búsqueda de plasmar nuevos sentidos en torno a las transformaciones recientes en la Argentina. Las producciones culturales toman posición en un sentido político específico, y no por ello predeterminado, en el que la creatividad actúa como un medio renovado de interpelación. En tal sentido, podríamos advertir algunos efectos y transformaciones que derivan de los aprendizajes y modos de participación de la década precedente. Longoni (2011) observa ciertas continuidades pero también transformaciones en la relación entre arte y política. Para la autora, el mayor impacto de 2001 en el cruce del arte y la política se produce no tanto dentro del circuito artístico sino más bien sobre los modos de hacer política. Por lo tanto, en los modos actuales de hacer política advertiríamos que la incorporación de la "dimensión creativa", tanto en los distintos repertorios de protesta social como de participación, se han vuelto centrales. Observamos que diversas producciones en Internet conquistan a la creatividad como un recurso y generan nuevas formas de interpelación e intercambio que, asimismo, resignifican sentidos acerca de este momento político, dando cuenta de su aggiornamiento en las sensibilidades y plataformas tecnológicas actuales.

Respecto del gobierno de Néstor Kirchner en particular, más allá de las críticas que se realizan desde distintas perspectivas, con respecto al lugar que asume la política durante este gobierno, Sarlo (2011: 226) sostiene que "se restituyó densidad a una política que, durante los años noventa, se había propuesto como administración de las cosas según las leyes del mercado. Frente al realismo (catastrófico) de los noventa, la pregnancia simbólica del kirchnerismo puede ser discutida en sus formas y en su tópica, pero no en la importancia que tomó como dinámica repolitizadora".

La idea de tomar partido en la batalla cultural frente a los intereses corporativos, como modo defensivo para preservar el modelo, ha sido bastante extendida en los últimos años como explicación recurrente de la politización de diversos sectores de la sociedad argentina, así como de la conformación de diversos colectivos en Buenos Aires. Otro acontecimiento, que implicó que otros jóvenes se sumaran a los que ya estaban militando, y que provocó que se volvieran hipervisibles para buena parte de los medios de comunicación aun contra su propia voluntad, fue el fallecimiento del ex presidente Néstor Kirchner el 27 de octubre de 2010 (Saintout, 2011).

Las mencionadas expresiones políticas y las movilizaciones que implicaron trajeron aparejadas diversas transformaciones que tuvieron impacto, entre otros tantos 


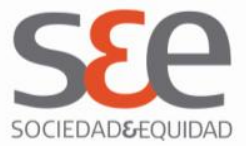

aspectos, en la subjetividad juvenil. Respecto de la participación juvenil en este período, y su comparación con la de la década precedente, diríamos entonces que se pasó de una sensación de desmovilización juvenil a un proceso de re-encantamiento con lo público.

En la contemporaneidad del escenario político de la Argentina, caracterizado en términos generales por un "clima de época" disímil a los antecedentes (los años sesenta y setenta o la llamada "transición a la democracia" en los ochenta), podemos señalar que suele reconocerse -sobre todo durante los últimos años- la emergencia de una conciencia ciudadana que, en contraposición a la hegemónica de la década del noventa (y sus perspectivas y caracterizaciones estigmatizantes, también hegemónicas, acerca de los jóvenes de la época), hace de base para la constitución de nuevas o reconfiguradas identidades políticas, las cuales en gran parte encuentran en el 19 y 20 de diciembre de 2001 -y en la Masacre de Puente Pueyrredón en junio de $2002^{2}$ - un punto de inflexión. Del mismo modo, encuentran en el kirchnerismo un acontecimiento político generacional de significativa relevancia -tanto para quienes están a favor o en contra del mismo. Aun con las salvedades que hay que realizar respecto de la heterogeneidad social, política y cultural que caracteriza a la Argentina, y cierta tendencia en los análisis que involuntariamente podrían transpolar fenómenos propios de las grandes y principales ciudades al resto de su territorio -realizando así generalizaciones erróneas-, nos preguntamos si con la emergencia del kirchnerismo se produjo cierta subjetividad política, acaso generacional (Núñez, 2011), que implicaría a generaciones superpuestas (Vommaro, 2011).

Un conjunto de políticas y medidas implementadas desde el gobierno nacional que se inicia en el año 2003 (Asignación Universal por Hijo, Ley de Servicios de Comunicación Audiovisual, el paso a la administración estatal de los fondos de jubilaciones, Ley de Matrimonio Igualitario, los juicios a los agentes de terrorismo de Estado, entre otras), aparecen como medidas destacadas en el escenario político argentino para explicar el cambio de escenario. Muchos jóvenes -algunos sin experiencia de militancia previa- se fueron incorporando al arco político del kirchnerismo, sobre todo durante los últimos años, en numerosos casos realizando una primera aproximación a través de herramientas tecnológicas para comunicarse en los sitios de redes sociales (SRS) y blogs, en sintonía con la creciente presencia en la cultura juvenil del uso de las TIC. La denominada "militancia virtual”, “militancia 2.0" o cibermilitancia favorecería, por lo tanto, al intercambio de información y potenciaría la proliferación de debates en torno a los jóvenes y su participación, así como su presencia en los debates de la agenda

\footnotetext{
${ }^{2}$ En aquella ocasión las fuerzas represivas del Estado asesinaron a Maximiliano Kosteki y Darío Santillán, jóvenes militantes que se constituyeron en emblemas del compromiso y de la lucha contra las políticas de ajuste (Saintout, 2011).
} 


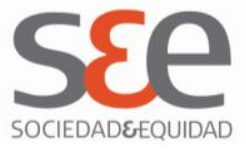

de gobierno. Se trata de una primera aproximación o puerta de entrada a la participación política a través de estas herramientas, que luego puede traducirse en una militancia de tipo territorial asociable a alguna de las nuevas organizaciones emergentes.

Por otro lado, existen organizaciones que directamente se han conformado en el espacio "virtual” y aun así perduran en el tiempo. Sin embargo, en numerosos casos este modo de intervención vendría a complementar la militancia territorial, e inclusive a potenciarla. Esto siempre y cuando los jóvenes cuenten con el acceso a las herramientas que así lo permitan (tales como blogs, sitios de redes sociales, etc.) y, sobre todo, se encuentren inmersos en un contexto político que produzca este tipo de renovado interés por la política y la participación. De este modo se produciría, hasta cierto punto, un movimiento autorreflexivo que favorecería la democratización de la palabra y la horizontalidad en los debates.

Si consideramos que la incorporación de formatos tecnológicos funcionaría como modo de soporte o superficie de la intervención, debate y construcción de sentidos colectivos, esto traería aparejado interrogantes vinculados a las TIC no siempre tenidos en cuenta. Se trata, siguiendo a Albornoz (2011), de incorporar también la dimensión política de estas tecnologías: los intereses económicos detrás de las mismas, sus usos sociales y posibles consecuencias (Garrido, 2011).

En cuanto a los contenidos de su participación, parecería que en muchos casos se trata de la organización en torno a demandas concretas, al ejercicio de derechos vinculados al presente en diálogo con la agenda política. Los jóvenes reconocen la convocatoria por parte del Estado en la medida en que entienden que a partir de la política es posible transformar la sociedad para generar mayores grados de soberanía y justicia social. Sin embrago, cuando pensamos en los jóvenes, debemos contemplar que realizan su socialización en instituciones e instancias diversas, que promueven ideasfuerza disímiles y, en algunos casos, antagónicas. El Estado mismo es una instancia de socialización heterogénea que compite con otras tantas instancias nucleares, tales como el mercado y las industrias culturales.

Entre las motivaciones iniciales de la participación, muchos jóvenes reconocen que el rol del ex presidente Néstor Kirchner ha resultado ser crucial:

Él solía hablar de la teoría del espiral. Como una especie de materialismo dialéctico entendía que su generación, que había intentado un cambio revolucionario en los años setenta, era ahora responsable, desde el Estado, de 


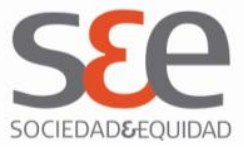

devolver a los jóvenes una forma perfeccionada de revolución pacífica (Lijalad, 2010).

La masiva presencia juvenil en el funeral de Kirchner pareció el resurgir de una militancia juvenil que muchos creían dormida. Pero, en realidad, aquel velorio iluminó con los flashes de los canales de noticias, en aquella plaza colmada, lo que algunos preferían dejar en las sombras (Lijalad, 2010).

Nacimos hijos del escepticismo y heredamos un legado de lucha. Néstor Kirchner nos dejaba, hace sólo un año, toda su vida servida, para explorarla e imitarla en sus mejores facetas. Porque sin dudas fue un ser humano. Excepcional pero humano. No podríamos, y menos en esta fecha, olvidar el destino que nos fue impuesto como generación. No podríamos hacerlo sin faltarnos el respeto a nosotros mismos y a su memoria. Luchamos y lucharemos para hacer de esta patria el lugar que él soñó para nosotros. Porque se fue sin terminarlo pero vive en nosotros y en nuestras victorias. Gracias Néstor. Ni un paso atrás ${ }^{3}$.

La proximidad e interpelación que generaba la figura de Néstor Kirchner se expresa no solo en la participación misma, sino en que los jóvenes lo definan y sientan “como a un par". Que reconozcan en él la capacidad de devolverles la fe en la política. En esta interpelación se refuerza la idea de "ser protagonista en el presente". Aparece fuertemente la idea del joven protagonista. 0 del llamado y la apertura para ocupar un lugar central en la Historia. Por otro lado, la microcultura política de las juventudes que se ubica en el arco político del kirchnerismo se apropia de cierta mística que hace posible tanto el aglutinamiento como la superación de contradicciones menores. De esta forma, se contribuye a sortear el obstáculo que se presenta en las sociedades actuales proclives a las "microsociedades" diferenciadas.

Desde el Estado, en instancias tales como la Dirección Nacional de Juventud, se realizan Jornadas y espacios participativos locales dirigidos a los jóvenes. El Estado, asimismo, genera instancias de comunicación que buscan visibilizar y difundir las experiencias de organización de las juventudes, tal como puede observarse en

${ }^{3}$ Disponible en https: / /www.facebook.com/generacion27deoktubre Publicado el 27 de octubre de 2011, a un año de la muerte de Néstor Kirchner. 


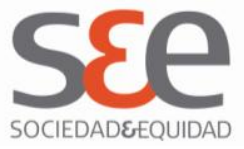

“Juventudes del Bicentenario" -publicación gratuita realizada por el Consejo Federal de Juventud.

Si pensamos este tipo de iniciativas desde una concepción de Estado amplia, resulta oportuno retomar las diferentes acepciones de Estado que desarrolla García Linera en La potencia plebeya..., ya que describe al Estado también como idea o creencia colectiva generalizada, es decir, como un sentido común de época que garantiza el consentimiento moral entre gobernantes y gobernados. Se trataría de ideas fuerza con carácter expansivo, entendidas como creencias en torno a las cuales están dispuestos a entregar tiempo, esfuerzo y trabajo para su materialización. Podríamos pensar que, entre estas ideas-fuerza, el rol de los jóvenes en la política es claramente una de ellas. Los jóvenes aparecen como sujetos políticos que, entre otros, ocupan un rol central en el proyecto, como puede evidenciarse incluso en algunos de los discursos de la Presidenta de la Nación: "Quiero agradecerles a todos los jóvenes de todas las agrupaciones y movimientos sociales de la Patria, que han sido la verdadera vanguardia de este Gobierno en sus momentos más difíciles" (Discurso en su reasunción el 10 de Diciembre de 2011) ${ }^{4}$.

En torno a la militancia política, cuando los jóvenes que se incorporan al kirchnerismo pasan a ocupar espacios de poder, se encuentran en situación de diálogo con los actores previamente constituidos. Pero, al mismo tiempo, tienen como objetivo plantear rumbos nuevos para un horizonte más igualitario que involucre un compromiso de índole colectiva. El mismo ex presidente Néstor Kirchner los interpelaba a superar el posibilismo: “A los jóvenes les digo que sean transgresores y que opinen. La juventud tiene que ser un punto de inflexión del nuevo tiempo" Discurso en la Plaza de los Dos Congresos el 15 de Julio de 2008).

Aquellos jóvenes que asumen roles de poder tienen, por un lado, la responsabilidad de mantener la base social de sustento que resulta clave para momentos difíciles, y por otro lado formar y formarse para roles de gestión futuros, al mismo tiempo correr y transgredir las fronteras políticas de lo posible. Los alcances y limitaciones de estas transformaciones son materia de debate y disputa política, así como un proceso abierto y en construcción. En definitiva, al igual que aquellos de antaño, los jóvenes son un síntoma de los tiempos que se viven (Urresti, 2000).

\footnotetext{
${ }^{4}$ Debemos considerar que esta necesidad o apertura por incorporar a los jóvenes se observa también en otros partidos políticos, como podemos observar, por ejemplo, en partidos como el PRO o Proyecto Sur: "Proyecto Sur afirma que la clave para nuestro futuro está en la incorporación de los jóvenes en la construcción de un proyecto nacional emancipador" (Juan Pablo Olsson, militante de Juventud Proyecto Sur, en Revista Caras y Caretas, Diciembre de 2010).
} 


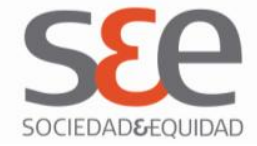

\section{Jóvenes y cibermilitancia en Buenos Aires: avances de investigación}

Para conocer la participación de los jóvenes y procurar construir una mirada desde la propia perspectiva de los actores involucrados, durante el mes de abril de 2012 hemos realizado vía Internet entrevistas semi-estructuradas a diez organizaciones involucradas en una cibermilitancia activa, y también a siete jóvenes de entre 18 y 30 años que se consideran militantes y participan de este modo. Durante ese mismo mes hemos participado de Foros de debate online en los que se ha discutido sobre cibermilitancia, sus alcances y perspectivas.

En primer lugar, los sitios de redes sociales en Internet como Facebook y Twitter aparecen considerados como escenario de debate, donde los jóvenes pueden expresarse libremente, en algunos casos en relación de complementariedad con respecto a los mensajes que circulan en los grandes medios y, en otros, como un aspecto táctico de la lucha política para la difusión de información, perspectivas y propuestas alternativas. En algunas oportunidades, estos sitios son mencionados como un espacio donde contrarrestar los efectos de los mensajes difundidos por los grandes medios, ya que por su dinámica la participación masiva en este tipo de redes podría tener influencia sobre los estados de ánimo colectivos. En algunos casos, se menciona que es posible contribuir a la conformación de una agenda pública instalando y debatiendo temáticas específicas. En otros, se habla de poder sortear cualquier tipo de censura con mayor facilidad, pero se reconoce que aún falta expandir estas posibilidades de expresión. Al respecto se menciona como ejemplo la autoconvocatoria de 678 Facebook a partir del conflicto desarrollado en torno a la Resolución 125 en Argentina. En este sentido, se destaca el valor que tienen los sitios de redes sociales en Internet en contextos de conflicto y disputa política, como por ejemplo en los casos del golpe de Estado en Honduras y las manifestaciones estudiantiles en Chile, donde las redes sociales ocuparon un rol importante para el intercambio de información y la organización. Asimismo, se hace hincapié en la importancia que adquiere la posibilidad de superar con mayor facilidad los límites espacio-temporales. Sin embargo, los sitios de redes sociales son considerados como herramientas, y su rol e implicancias no son problematizadas en las condiciones de desarrollo y propiedad actuales (Garrido, 2012).

Según la clasificación de la participación online sugerida por Gomes (2011), en numerosos casos las acciones realizadas por los jóvenes serían efectivamente formas de participación en la vida pública $y / o$ el juego político, es decir, acciones de participación. La red social Facebook aparece como la herramienta que más utilizan los militantes entrevistados, aunque quienes militan en partidos políticos también destacan 


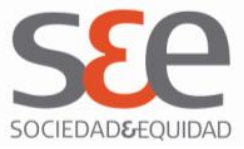

el rol que tienen para la difusión y la organización los sitios Web o los blogs propios de la agrupación:

La más importante es Facebook, el Twitter no sirve (aunque nosotros tenemos uno), los blogs ya no se usan tanto, Facebook tiene la capacidad de abarcar todo, tenés fotos, notas (que vienen a reemplazar a los blogs), y por sobre todo la juventud es la que más usa Facebook (...) El mail ya no se usa tanto puesto que Facebook tiene un sistema de mensajes privados. Lo que más utilizamos es derivaciones a páginas web mediante links, pero siempre a través de Facebook (Agrupación política del Gran Buenos Aires).

Los jóvenes entrevistados reconocen que la cibermilitancia ocupa un papel fundamental debido a que permite una mayor difusión de sus actividades y propuestas, pero que, sin embargo, no reemplaza ni tiene los mismos alcances que la militancia denominada "tradicional" o territorial. En la cibermilitancia se verían soslayados aspectos fundamentales vinculados a la comunicación directa y las dimensiones de lo corporal.

Es fundamental tener en cuenta que a la hora de militar en los barrios más humildes, de nada sirve Internet. Lo que hacemos es ir, volantear, tener contacto con los vecinos, delegados, comuneros, charlar, debatir personas con personas (Laura, 27 años, Buenos Aires).

Hay más razones afuera que adentro de una computadora para participar en política y en ese sentido hay que estar en el territorio real para entender las necesidades, las carencias, las aspiraciones y también para dejarse atravesar por las inefables sensaciones que despierta el latir de la masa y el compartir un objetivo común con gente totalmente heterogénea (Germán, 30 años, Buenos Aires).

En las redes no se huele, no se palpa la militancia (Pablo, 26 años, militante de grupo socio-político, Buenos Aires). 


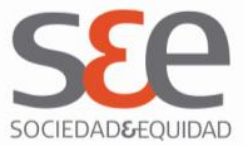

Entre quienes forman parte de la organización y participación de la cibermilitancia las posiciones son variadas. Están quienes advierten que se trata de un medio para lograr fines determinados y quienes encuentran que la misma es en sí misma relevante. También están quienes remarcan las limitaciones sin desconocer por ello sus potenciales:

La militancia virtual ocupa el lugar que en otras épocas ocupaba la discusión en las Unidades Básicas o locales políticos. Se debate más en internet que en el territorio. Creo que es la herramienta que da sustento teórico a la acción concreta en el territorio (Organización independiente de Buenos Aires).

Hoy es igual de importante que cualquier otro tipo de militancia. Porque la gente adoptó el uso de la web en sus vidas cotidianas, se ve tanto un afiche en la calle como en el muro de tu Facebook (Organización independiente de Buenos Aires).

Creo que funcionan como un buen complemento. La política es la mejor herramienta que tienen los pueblos para poder transformar la realidad. Y la militancia es llevar a la práctica la política. La militancia territorial o tradicional es aquella que ejercemos todos los días. En nuestros puestos de trabajo, en el barrio, en una fábrica, una cooperativa o en la universidad. Somos militantes de un proyecto político, colectivo. Llevamos nuestra verdad relativa en cada ámbito donde nos desenvolvemos. Por eso somos comunicadores. Esta militancia es irremplazable y es la primordial. La militancia virtual es una herramienta valiosa que, al actuar como complemento, permite que esa verdad relativa, ese mensaje que los militantes llevan, pueda multiplicarse. Amplía el nivel de convocatoria (Organización política juvenil, Buenos Aires).

Creo que la mayor dificultad es poder llegar a los demás; creo que si estamos políticamente activando es necesario el contacto con gente y el poder hablar cara a cara, el ver, relacionarse, transmitir, creo que Internet impide mucho eso y saca la parte superficial de todos los que conversan; creo que es más difícil ocultar algo 


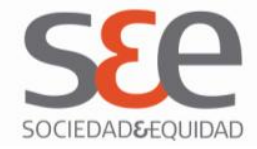

cuando estás frente a los demás (Mariana, militante sindical, 20 años, Gran Buenos Aires).

\section{A modo de conclusión}

Si bien la militancia juvenil partidaria ocupa un lugar fundamental para el proceso político en curso, resulta atendible también preservar y potenciar aquellas formas de participación política más novedosas que se encuentran por fuera de la misma. Siguiendo a Žižek (2011), la participación restringida a los mecanismos democráticos de tipo institucional obstaculizaría ciertas posibilidades de renovación radical que genere nuevos lenguajes y sentidos colectivos. Dado que incluso los jóvenes "repolitizan la política desde afuera, sirviéndose para ello de los propios símbolos de la llamada sociedad de consumo" (Núñez, 2010: 115), es lícito no descartar a priori ninguna iniciativa en ciernes. Incluso el estudio de estas formas espontáneas y novedosas resulta un insumo relevante para el diseño de políticas públicas dirigidas a las juventudes en sentido amplio.

Por otro lado, en la militancia juvenil partidaria suelen reconocerse rasgos de "lo viejo", aunque con sus lógicas particulares afines a los tiempos actuales y sus grados de autonomía. Se trataría en todo caso de una convivencia de "lo viejo" y "lo nuevo" que es preciso ponderar. Esto no significa evaluación alguna respecto de un modo de participación "preferible" ni mucho menos, se trata incluso de modos de participación en vinculación, comunicación e intercambio, que se retroalimentan y potencian entre sí.

Asimismo, creemos que desarrollar una perspectiva de tipo generacional, tanto para el abordaje de los sujetos implicados como para el rastreo de las lecturas de los conflictos y escenarios políticos, sortea el desacertado presupuesto de cierta homogeneidad en los jóvenes, en sociedades complejas como las actuales, y nos permite realizar un análisis sociológico que habilita (re)pensar las continuidades, rupturas y significaciones sociales en este proceso político en curso (Hamawi et al, 2011).

Por otro lado, las comunicaciones P2P (punto a punto) eludirían hasta cierto punto las posibilidades de control institucional y la sujeción a los medios de comunicación tradicionales. Si bien este tipo de comunicación mediada por la computadora expande las fronteras de alcance y difusión posibles, implica una importante restricción a dimensiones de la militancia que algunos de los entrevistados refieren como fundamentales del vínculo y de la construcción política. Entre las potencialidades de las nuevas TIC como matriz socio-técnica, observamos que los sitios de redes sociales en Internet de consumo masivo, tal como es el caso de Facebook, 


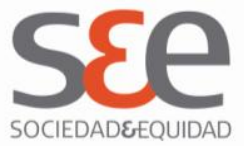

hacen las veces de soporte de formas de agencia individual y colectiva que aquí utilizamos bajo la denominación de cibermilitancia. En los casos analizados, la cibermilitancia se encuentra en directa vinculación con formas de militancia llamadas "tradicional" o territorial. En este sentido, podemos afirmar que las nuevas TIC funcionan como soporte de cierta militancia y de la construcción de situaciones articuladoras de necesidades e intereses comunes sobre las que es preciso seguir indagando.

Para finalizar, es importante resaltar que en el actual contexto de crisis económica global, esta repolitización resulta ser auspiciosa para la construcción colectiva nacional y la preservación de la soberanía. Que se pueda avanzar en términos cualitativos y programáticos, y que las nuevas generaciones puedan convertirse en una generación política que componga su propio lenguaje, vuelva irreversibles las conquistas logradas, pero que al mismo tiempo pueda hacerse cargo de las transformaciones pendientes, responde, en todo caso, a un proyecto de sociedad que en su construcción política, sus posibilidades y alcances involucra a todos y cada uno de sus integrantes.

\section{Referencias bibliográficas}

Albornoz, Luis (comp.) (2011). Poder, medios, cultura: una mirada crítica desde la economía política de la comunicación. Buenos Aires: Paidós.

Becerra, Martín y Guillermo Mastrini (2011). "Estructura, concentración y transformaciones en los medios del Cono Sur latinoamericano". Comunicar, $N^{\circ} 36, \mathrm{v}$. XVIII, 2011: 51-59. [Documento en línea]. Disponible desde Internet en: <http://rabida.uhu.es/dspace/bitstream/handle/10272/4823/estructura_concentracion _transformaciones.pdf?sequence=2>

Castells, Manuel (2001). La era de la información. Economía, sociedad y cultura. El poder de la identidad, vol. 2. Buenos Aires: Siglo XXI.

Dantas, Marcos (2003). "Informaçao e trabalho no capitalismo contemporáneo". Lua Nova: Revista de Cultura e Politica, N60, 2003: pp. 5-44. 


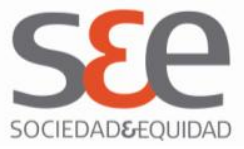

García Linera, Álvaro (2008). La potencia plebeya: Acción colectiva e identidades indígenas, obreras y populares en Bolivia. Buenos Aires: CLACSO-Prometeo.

Garrido, Natalia (2009). "La utopía en los tiempos de la incertidumbre: los nuevos gobiernos en América Latina y los jóvenes en el espacio público". XXVII Congreso Alas Congreso Internacional de la Asociación Latinoamericana de Sociología, Buenos Aires.

Garrido, Natalia (2011). "Identidades juveniles y consumos culturales en Internet". IX Jornadas de Sociología: Capitalismo del siglo XXI, crisis y reconfiguraciones. Luces y sombras en América Latina. Carrera de Sociología, Facultad de Ciencias Sociales, Universidad de Buenos Aires, CABA, 8 al 12 de agosto de 2011.

Garrido, Natalia (2012). "Identidades y 'cibercultura': una aproximación a los consumos culturales en los sitios de redes sociales en internet". En Ana Wortman (Comp.), Mi Buenos Aires Querido. Entre la democratización cultural y la desigualdad educativa. Pp. 85-103. Buenos Aires: Prometeo.

Gomes, Wilson (2011). "Participacao política online: questoes e hipótesis de trabalho. En Maia Moreira, Wilson Gomes y Francisco Almeida Marques (orgs.), Internet e Participacao Polítca no Brasil, pp-19-45. Porto Alegre: Sulina.

Hamawi, Rodolfo, et. al (2011). Qué es el kirchnerismo. Escritos desde una época de cambio. Buenos Aires: Continente.

Hopenhayn, Martín (2012). "Los jóvenes perciben que hay vacíos por llenar en la política". Entrevista para el diario Página 12, lunes 2 de enero de 2012. [Documento en línea]. Disponible desde internet en: <http://www.pagina12.com.ar/diario/dialogos/21184583-2012-01-02.html>

Lijalad, Ari (2010). "Borrachos de juventud". Caras y Caretas, $N^{\circ}$ 2253, año 49, diciembre de 2010. pp. 9-21. 


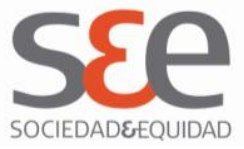

Longoni, Ana (2011). "¿Qué queda hoy del activismo artístico?". Revista Ñ, 16 de diciembre de 2011. [Documento en línea]. Disponible desde Internet en: <http://www.revistaenie.clarin.com/ideas/Cultura_de_la_crisis_0_610738943.html>

Núñez, Pedro (2010). "Política y poder en la escuela media: disputas en torno a la 'participación juvenil' en el espacio escolar". En Florencia Saintout (Comp.), Jóvenes argentinos: pensar lo político. Buenos Aires: Prometeo.

Núñez, Pedro (2011). "La política en la escuela: sensibilidades juveniles, justicia y derechos". En Juventudes en la Argentina y América Latina. Cultura, política $e$ identidades del siglo XX al XXI. CAICYT-CONICET, Argentina. [Documento en línea]. Disponible desde Internet en: <http://cursos.caicyt.gov.ar>

Roldán. Martha (2005). "División internacional-informacional del trabajo y configuraciones tempo espaciales. Explorando claves del desarrollo ausente argentino". Sociología del Trabajo. Nueva época, N 53, invierno de 2004-2005. Madrid: Siglo XXI Editores.

Sader, Emir (2009). A nova toupeira: Os caminhos da esquerda latinoamericana. San Pablo: Boitempo.

Saintout, Florencia (2006). Juventud: el futuro llegó hace rato. La Plata: Universidad de La Plata.

Saintout, Florencia (2011). "Generaciones contemporáneas: Identidades juveniles a las orillas de la ciudadanía". En Juventudes en la Argentina y América Latina. Cultura, política e identidades del siglo XX al XXI. CAICYT CONICET, Argentina. [Documento en línea]. Disponible desde Internet en: <http://cursos.caicyt.gov.ar> 


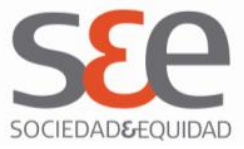

Sarlo, Beatriz (2011). La audacia y el cálculo. Kirchner 2003-2010. Buenos Aires: Sudamericana.

Toer, Mario, Martínez Pablo, Agilda Leandro, Burbano de Lara Agustín, Garrido Natalia Goldstein Ariel, Montero Federico y Salas Amílcar (2010). "Los desafíos del pensamiento progresista en el actual contexto latinoamericano. Hegemonía, Estado y Democracia". Trabajo presentado al I Congreso Internacional Extraordinario de Ciencia Política, San Juan, Argentina.

Unidad de Coordinación de Políticas de Juventud (UCPJ), Encuesta Joven 2008. [Documento en línea]. Disponible desde Internet en: <http://www.generacionba.gov.ar/generacionba/observatorio/pdf/encuestas/encuesta _joven_08.pdf>

Urresti, Marcelo (2000). "Paradigmas de participación juvenil: un balance histórico". En Sergio Balardini (Coord.), La participación social y política de los jóvenes en el horizonte del nuevo siglo, pp. 177- 206. Buenos Aires: CLACSO-Asdi.

Urresti, Marcelo (2008). Ciberculturas juveniles: los jóvenes, sus prácticas y sus representaciones en la era de Internet. Buenos Aires: La Crujía.

Virno, Paolo (2003). Gramática de la multitud. Para un análisis de las formas de vida contemporáneas.Buenos Aires Traficantes de sueños.

Wortman, Ana (Comp.) (2009). Entre la política y la gestión de la cultura y el arte: nuevos actores en la Argentina contemporánea. Buenos Aires: Eudeba.

Vommaro, Pablo (2011). "Aproximaciones a las relaciones entre juventudes, políticas y culturas en la Argentina y en América Latina actuales: miradas desde las modalidades de participación política de los jóvenes en movimientos sociales". En Juventudes en la Argentin y América Latina. Cultura, política e identidades del siglo XX al XXI. CAICYT- 


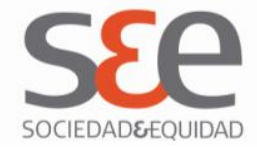

CONICET, Argentina. [Documento en línea]. Disponible desde Internet en: <http://cursos.caicyt.gov.ar>

Žižek, Slavoj (2011). "La revuelta de la burguesía asalariada". Amauta, 24 de enero del 2012. [Documento en línea]. Disponible desde Internet en: <http://revistaamauta.org/2012/01/la-revuelta-de-la-burguesia-asalariada/>

\section{Fuentes consultadas:}

Dirección Nacional de Juventud: <http://www.juventud.gov.ar/notas.php?id=139> Discursos completos de la Presidenta: <http://discursos.telam.com.ar/?p=831> Facebook: <www.facebook.com>

Página 12: <www.pagina12.com.ar>

Revista Caras y Caretas. La revista de la Patria, N 2253, año 49, diciembre 2010. Revista Juventudes del Bicentenario, N 1, 2 y 3 del año 2011. 